\title{
Stage III Nasopharyngeal Carcinoma AJCC v8
}

National Cancer Institute

\section{Source}

National Cancer Institute. Stage III Nasopharyngeal Carcinoma A/CC v8. NCI Thesaurus.

Code C132819.

Stage III includes: (T1, N2, M0); (T0, N2, M0); (T2, N2, M0); (T3, NO, M0); (T3, N1, M0); (T3, N2, M0). T1: Tumor confined to the nasopharynx, or tumor extending to oropharynx and/or nasal cavity without parapharyngeal involvement. T0: No tumor identified, but EBV-positive cervical node(s) involvement is present. T2: Tumor with extension to parapharyngeal space, and/or adjacent soft tissue involvement (medial pteryg oid, lateral pterygoid, prevertebral muscles). T3: T umor infiltrating bony structures at skull base, cervical vertebrae, pterygoid structures, and/or paranasal sinuses. N0: No regional lymph node metastasis. N1: T umor with unilateral metastasis in cervical lymph node(s), and/or unilateral or bilateral metastasis in retropharyng eal lymph node(s), $6 \mathrm{~cm}$ or smaller in greatest dimension, above the caudal border of cricoid cartilage. N2: T umor with bilateral metastasis in cervical lymph node(s), $6 \mathrm{~cm}$ or smaller in greatest dimension, above the caudal border of cricoid cartilage. M0: No distant metastasis. (AJCC 8th ed.) 